\title{
Decision Support System Fuzzy Analytic Hierarchy Process Method Studi Kasus Pemilihan Vendor Kemasan Terbaik
}

\author{
Najmuddin $^{1}$, Arief Herdiansah ${ }^{2}$ \\ ${ }^{1}$ Program Studi Informatika, Fakultas Teknik, Universitas Primagraha, Jl. Raya Trip Jamak Sari, Kota Serang, Banten \\ ${ }^{2}$ Program Studi Teknik Informatika, Fakultas Teknik, Universitas Muhammadiyah Tangerang, Jl. Perintis Kemerdekaan 1/33 \\ Cikokol Kota Tangerang, Banten \\ Co Responden Email: arief_herdiansah@umt.ac.id
}

Article history

Received March 08, 2021

Revised June 08, 2021

Accepted June 15, 2021

Available online June 20, 2021

Keywords

$S P K$,

Fuzzy AHP

Packaging,

Vendor

\begin{abstract}
Packaging is a component that must be considered because it can affect (visually) the customer in determining the decision to buy the product being offered. The quality of the raw materials used, the shape and aesthetics of the packaging must be in accordance with the wishes of customers who want the safety and beauty of product packaging without affecting the quality of the food stored in it. To be able to help companies have quality packaging, a decision support system (SPK) is needed that can quickly and precisely choose the best packaging vendor. The results of this study have proven that the Fuzzy Analytic Hierarchy Process Method has been able to assist users in the process of selecting the best packaging vendor.
\end{abstract}

\begin{abstract}
Kemasan merupakan sebuah komponen yang harus diperhatikan karena dapat mempengaruhi (secara visual) pelanggan dalam menentukan keputusan untuk membeli produk yang ditawarkan. Kualitas bahan baku yang digunakan, bentuk dan estetika dari kemasan harus lah sesuai dengan keinginan pelanggan yang menginginkan keamanan dan keindahan dari kemasan produk tanpa mempengaruhi kualitas makanan yang tersimpan didalamnya. Untuk dapat membantu perusahaan memiliki kemasan yang berkualitas dibutuhkan sebuah sistem penunjang keputusan (SPK) yang dapat dengan cepat dan tepat memilih vendor packaging terbaik. Hasil penelitian ini telah membuktikan bahwa metode Fuzzy AHP telah dapat membantu pengguna dalam proses pemilihan vendor kemasan terbaik.
\end{abstract}

\section{PENDAHULUAN}

Standarisasi dan kualitas kemasan (packaging) yang digunakan dalam sebuah perusahaan khususnya yang bergerak di industry makanan sangat lah penting, karena kemasan dapat menjadi awal penilaian konsumen terhadap suatu barang yang diperdagangkan. Dengan standarisasi dan kualitas kemasan yang terjaga dan menarik dapat menambah daya tarik pelanggan untuk membeli produk yang diperdagangkan. Banyak pihak mengatakan kemasan suatu produk pada akhirnya merupakan sampah dan meningkatkan beban biaya produksi sebuah produk, tetapi banyak orang juga menyakini pentingnya kemasan dalam menunjang suksesnya pemasaran sebuah produk. Kemasan yang digunakan dalam sebuah produk hendaknya dapat memenuhi keinginan konsumen dan dapat memberikan perlindungan produk dengan baik dari cuaca, perubahan suhu, serangga, bakteri dan lain-lain. Struktur kemasan juga hendaknya mudah dibuka, mudah ditutup dan mudah dibawa serta memiliki bentuk dan ukuran menarik sesuai dengan kebutuhan sehingga dapat menciptakan daya tarik visual bagi pelanggan.

Menurut Wakil Menteri Perindustrian (Wamenperin) Alex S.W. Retraubun di Indonesia sebanyak $40 \%$ kemasan terbuat dari kertas dan karton, 34\% terbuat dari kemasan plastic, $14 \%$ terbuat dari kemasan logam dan $11 \%$ terbuat dari kemasan gelas. 
Penelitian ini merupakan penelitian terapan pada sebuah perusahaan yang bergerak di industri makanan, dimana penelitian ini akan menganalisa bagaimana perusahaan dapat menentukan vendor kemasan (packaging) yang sesuai dengan produk yang dihasilkan menggunakan Sistem Pendukung Keputusan (Decision Support System/DSS) dengan metode Fuzzy Analytic Hierarchy Process berdasarkan kriteria yang telah ditentukan berdasarkan keinginan pemilik perusahaan dan keinginan pelanggan pada umumnya, antara lain: diinginkan kemasan yang digunakan terbuat dari bahan food grade packaging yang tidak mencemari makanan dalam kemasan tersebut sehingga tidak membahayakan pelanggan yang mengkonsumsi makanan dalam kemasan tersebut.

Penelitian ini meliputi proses perancangan sistem menggunakan UML (Unified Modeling Language) yang merupakan bahasa pemodelan standar yang terdiri dari sekumpulan diagram terintegrasi, dikembangkan dalam rangka membantu pengembang sistem dan perangkat lunak untuk menentukan, memvisualisasikan, membangun, dan mendokumentasikan sistem perangkat lunak yang dikembangkan. Untuk dapat menghasilkan sebuah aplikasi Decision Support System (DSS) dengan hasil akurat perusahaan membutuhkan standarisasi pembobotan penilaian (Herdiansah et al., 2019).

\section{KAJIAN LITERATUR DAN PEGEMBANGAN HIPOTESIS}

Berikut ini beberapa literatur studi terdahulu berkaitan dengan peneltian tentang pengembangan Decision Support System (DSS) metode Fuzzy Analytic Hierarchy:

Tabel 1. Tabel Literatur Studi

\begin{tabular}{|c|c|c|c|c|}
\hline No & Peneliti & Judul & Metode & Kriteria \\
\hline 1 & $\begin{array}{l}\text { Norhikmah, Rumini, } \\
\text { Henderi } \\
\text { Seminar Nasional Teknologi } \\
\text { Informasi dan Multimedia } \\
\text { 2013. STMIK AMIKOM } \\
\text { Yogyakarta, 19/01/2013 } \\
\text { ISSN: 2302-3805 }\end{array}$ & $\begin{array}{l}\text { Metode Fuzzy } \\
\text { AHP dalam } \\
\text { penerapan sistem } \\
\text { pendukung } \\
\text { keputusan }\end{array}$ & $\begin{array}{l}\text { Fuzzy } \\
\text { Analytical } \\
\text { Hierarchy } \\
\text { Process } \\
\text { (Fuzzy } \\
\text { AHP) }\end{array}$ & \begin{tabular}{ll}
\multicolumn{2}{l}{ Kriteria: } \\
1. & Team Work \\
2. & Inisiatif \\
3. & Attitude \\
Sub & Kriteria: \\
1. & Baik \\
2. & Cukup \\
3. & Kurang
\end{tabular} \\
\hline 2 & $\begin{array}{l}\text { Saifulloh, Kusrini } \\
\text { Cogito Smart Journal, FIK } \\
\text { Univ Klabat. VOL 2. NO } 2 . \\
\text { DESEMBER 2016. } \\
\text { ISSN: 2541-2221 } \\
\text { e-ISSN: } 2477-8079\end{array}$ & $\begin{array}{l}\text { Sistem Pendukung } \\
\text { Pengambilan } \\
\text { Keputusan } \\
\text { Penentuan } \\
\text { Beasiswa } \\
\text { Menggunakan } \\
\text { Metode F-AHP }\end{array}$ & $\begin{array}{l}\text { Fuzzy } \\
\text { Analytical } \\
\text { Hierarchy } \\
\text { Process } \\
\text { (Fuzzy } \\
\text { AHP) }\end{array}$ & \begin{tabular}{ll}
\multicolumn{2}{l}{ Kriteria: } \\
1. & Prestasi \\
2. & Ekonomi \\
3. & Inklusi
\end{tabular} \\
\hline 3 & $\begin{array}{l}\text { Wahyudi Setiawan, Reny } \\
\text { Pujiastutik } \\
\text { Seminar Nasional Sains dan } \\
\text { Teknologi } 2015 \text {. } \\
\text { FT Univ Muhammadiyah } \\
\text { Jakarta. } 17 / 11 / 2015 \text {. } \\
\text { ISSN : } 2407-1846 \text {. } \\
\text { e-ISSN : } 2460-8416 \text {. }\end{array}$ & $\begin{array}{l}\text { Penerapan } \\
\text { Metode Fuzzy } \\
\text { Analytical } \\
\text { Hierarchy } \\
\text { Process Untuk } \\
\text { Pemilihan Spplier } \\
\text { Batik Madura. }\end{array}$ & $\begin{array}{l}\text { Fuzzy } \\
\text { Analytical } \\
\text { Hierarchy } \\
\text { Process } \\
\text { (Fuzzy } \\
\text { AHP) }\end{array}$ & \begin{tabular}{ll}
\multicolumn{2}{l}{ Kriteria: } \\
1. \\
2. & Harg Pembayaran \\
3. & Diskon \\
4. & Kecepatan Tanggap \\
5. & Komunikasi \\
6. & Informasi Produk \\
7. & Layanan Komplain \\
8. Jumlah Pengiriman \\
9. & Waktu Pengiriman \\
10. & Kualitas Produk \\
11. & Tingkat Kecacatan \\
12. & Jenis Transportasi \\
13. & Waktu Transportasi \\
\end{tabular} \\
\hline
\end{tabular}




\begin{tabular}{|l|l|l|l|l|}
\hline 4 & Skolastika S. Igon, Irya & Perancangan & Fuzzy & Kriteria: \\
& Wisnubhadra, B. Yudi & Sistem Pendukung & Analytical & 1. Kemampuan \\
Dwiandiyanta & Pengambilan & Hierarchy & 2. Kondisi Ekonomi \\
& Keputusan & Process & 3. Jaminan \\
& Seminar Nasional Teknologi & Dengan Metode & (Fuzzy & 4. Modal \\
& Informasi dan Komunikasi & Fuzzy Analytical & AHP) & 5. Karakter \\
& (SENTIKA) 2014. & Hierarchy & & \\
& Yogyakarta, 15/03/2014. & Process dalam & & \\
ISSN: 2089-9813 & Penyeleksian & & \\
& Pemberian Kredit & & \\
\hline
\end{tabular}

Berdasarkan literatur studi yang peneliti gunakan dalam penelitian ini, Hipotesis yang peneliti perkirakan adalah: hasil perhitungan Decission Support System (DSS) dengan metode Fuzzy Analytic Hierarchy Process sangat memperhatikan kekonsistenan dari hasil proses perhitungan yang dapat dilihat berdasarkan nilai /hasil akhir perhitungan (bobot global) dari semua kriteria yang didefinisikan. Penentuan bobot setiap kriteria dilakukan berdasarkan nilai skala yang ditentukan oleh pengambil keputusan dengan melihat relatif kepentingan dari setiap kriteria. Pemberian nilai skala akan dipengaruhi preferensi dari setiap proses pengambil keputusan.

\section{TINJAUAN PUSTAKA}

Kemasan (packaging) merupkan suatu bentuk kegiatan yang melibatkan desain serta produk, yang menjadikan kemasan tersebut berfungsi untuk melindungi produk yang disimpan di dalamnya (Kotler \& Amstrong, 2012). Pemilihan kemasan (packaging) sebuah produk sangat penting karena secara visual akan dapat mempengaruhi keinginan pelanggan membeli produk yang dipasarkan.

Sistem merupakan sekumpulan unsur/elemen yang saling berkaitan, saling mempengaruhi dalam melakukan kegiatan bersama dalam rangka mencapai sebuah tujuan. Sedangkan sistem informasi adalah suatu hal yang saling berhubungan satu dengan lainnya yang akhirnya menghasilkan sebuah informasi/data yang berguna bagi orang yang dituju sesuai dengan peruntukannya (Herdiansah, 2020). Menejemen Sistem informasi yang baik berhubungan erat dengan pengolahan data yang baik. pengolahan data yang masih belum terkomputerisasi dengan baik akan mengakibatkan kualitas informasi yang dihasilkan kurang akurat (Fitriawati et al., 2019).
AHP (Analytic Hierarchy Process ) tradisional merupakan sebuah sistem informasi yang menggunakan teknik keputusan multikriteria dengan pendekatan hierarkis untuk mengevaluasi nilai kepercayaan (Saraswat \& Chaurasia, 2013). Metode AHP mengasumsikan bahwa pembuat keputusan dapat memberikan estimasi poin yang tepat dari preferensi mereka untuk alternatif. Oleh karenanya metode ini tidak cocok untuk skenario ketika ada ketidakpastian yang tinggi dalam penilaian pengambil keputusan (Yaraghi et al., 2015). Decision Support System (DSS) metode Fuzzy Analytic Hierarchy Process merupakan sebuah metode pengembangan dari metode AHP (Analytic Hierarchy Process ) tradisional yang dapat digunakan untuk menghasilkan sebuah informasi yang dapat digunakan dalam proses pengambilan keputusan.

Pemilihan pemasok adalah sebuah aktivitas yang cukup rumit, oleh karena itu diperlukan sebuah metode yang tepat untuk mendapatkan pilihan yang terbaik. Proses pemilihan pemasok bertujuan untuk menentukan pemasok yang sesuaii dan tepat agar dapat memenuhi kebutuhan perusahaan dan dapat mengurangi resiko kurangnya bahan baku. Pemilihan pemasok yang tepat tidak hanya pemasok yang dapat memberikan material yang berkualitas, tepat waktu, dan harga terjangkau namun juga harus memberikan service yang optimal baik dari segi responsive, kelancaran komunikasi dan informasi (Yoserizal, 2012).

Salah satu kriteria yang sering digunakan untuk menilai vendor adalah Dickson's Vendor Selection Criteria akan tetapi keputusan akhir tetap ada pada orang yang menjadi penanggung jawab memilih vendor (pemasok) pada perusahaan tersebut. Rata-rata perusahaan menggunakan kriteria yang bersifat umum, seperti kualitas produk, pengiriman, harga 
produk dan kapabilitas produksi. Tabel 2 berikut adalah kriteria yang diklasifikasikan sebagai logistik, teknologi, kerjasama bisnis dan menjalankan bisnis dengan tujuan untuk membuat model yang membedakan antara kriteria kualitatif dan kuantitatif (Stevic, 2017).

Tabel 2. Tabel Review Kriteria Vendor (Stevic, 2017)

\begin{tabular}{|c|c|c|c|c|c|c|c|c|c|c|c|c|c|c|c|c|c|c|c|c|c|c|c|c|}
\hline $\begin{array}{l}\text { Criteria } \\
\text { References }\end{array}$ & $\mathbf{A}$ & B & C & D & $\mathbf{E}$ & $\mathbf{F}$ & $\mathbf{G}$ & $\mathbf{H}$ & I & $\mathbf{J}$ & $\mathbf{K}$ & $\mathbf{L}$ & $\mathbf{M}$ & $\mathbf{N}$ & $\mathbf{O}$ & $\mathbf{P}$ & $\mathbf{Q}$ & $\mathbf{R}$ & $\mathbf{S}$ & $\mathbf{T}$ & $\mathbf{U}$ & $\mathbf{V}$ & $\mathbf{W}$ & $\mathbf{X}$ \\
\hline $\begin{array}{l}\text { Price of } \\
\text { material }\end{array}$ & $\mathrm{x}$ & & $\mathrm{x}$ & $\mathrm{x}$ & & $\mathrm{x}$ & $\mathrm{x}$ & & $\mathrm{x}$ & & & $\mathrm{x}$ & $\mathrm{x}$ & & $\mathrm{x}$ & $\mathrm{x}$ & $\mathrm{x}$ & $\mathrm{x}$ & $\mathrm{x}$ & $\mathrm{X}$ & $\mathrm{x}$ & $\mathrm{x}$ & $\mathrm{x}$ & \\
\hline $\begin{array}{l}\text { Financial } \\
\text { stability }\end{array}$ & $\mathrm{x}$ & $\mathrm{x}$ & $\mathrm{x}$ & $\mathrm{x}$ & $\mathrm{x}$ & $\mathrm{x}$ & $\mathrm{x}$ & & $\mathrm{x}$ & & & & $\mathrm{x}$ & & $\mathrm{x}$ & & $\mathrm{x}$ & & & $\mathrm{x}$ & $\mathrm{x}$ & & $\mathrm{x}$ & \\
\hline $\begin{array}{l}\text { Method of } \\
\text { payent }\end{array}$ & & & & & & & $\mathrm{x}$ & $\mathrm{x}$ & & & & & & & & & & $\mathrm{x}$ & & & $\mathrm{x}$ & & & \\
\hline $\begin{array}{l}\text { Price of } \\
\text { transport }\end{array}$ & & & $\mathrm{x}$ & & & & $\mathrm{x}$ & $\mathrm{x}$ & $\mathrm{x}$ & $\mathrm{x}$ & & & $\mathrm{x}$ & & & & & & & $\mathrm{x}$ & & & & \\
\hline $\begin{array}{l}\text { Volume } \\
\text { discounts }\end{array}$ & & & & & & & & & $\mathrm{x}$ & & & & & & & & & & & & & & & \\
\hline Delivery time & & $\mathrm{x}$ & $\mathrm{x}$ & $\mathrm{x}$ & & $\mathrm{x}$ & $\mathrm{x}$ & $\mathrm{x}$ & $\mathrm{x}$ & & $\mathrm{x}$ & $\mathrm{x}$ & $\mathrm{x}$ & & $\mathrm{x}$ & $\mathrm{x}$ & $\mathrm{x}$ & $\mathrm{x}$ & $\mathrm{x}$ & $\mathrm{x}$ & $\mathrm{x}$ & $\mathrm{x}$ & $\mathrm{x}$ & \\
\hline Reliability & $\mathrm{x}$ & $\mathrm{x}$ & $\mathrm{x}$ & & & $\mathrm{x}$ & & $\mathrm{x}$ & $\mathrm{x}$ & & & & $\mathrm{x}$ & & $\mathrm{x}$ & & & & & & & $\mathrm{x}$ & & \\
\hline Flexibility & & $\mathrm{x}$ & $\mathrm{x}$ & & & & & $\mathrm{x}$ & $\mathrm{x}$ & & $\mathrm{x}$ & & & & $\mathrm{x}$ & & & & & & $\mathrm{x}$ & $\mathrm{x}$ & & \\
\hline $\begin{array}{l}\text { Logistics } \\
\text { capacity }\end{array}$ & & & & $\mathrm{x}$ & $\mathrm{x}$ & & $\mathrm{x}$ & & $\mathrm{x}$ & $\mathrm{x}$ & $\mathrm{x}$ & & $\mathrm{x}$ & $\mathrm{x}$ & & & $\mathrm{x}$ & & $\mathrm{x}$ & & $\mathrm{x}$ & & $\mathrm{x}$ & $\mathrm{x}$ \\
\hline $\begin{array}{l}\text { The } \\
\text { precentage of } \\
\text { correct } \\
\text { realization of } \\
\text { delivery }\end{array}$ & & & & & & & $\mathrm{x}$ & & & & & & & & & & & & & $\mathrm{x}$ & $\mathrm{x}$ & $\mathrm{x}$ & & \\
\hline $\begin{array}{l}\text { Quality of } \\
\text { material }\end{array}$ & $\mathrm{x}$ & & $\mathrm{x}$ & $\mathrm{x}$ & & $\mathrm{x}$ & $\mathrm{x}$ & & $\mathrm{x}$ & & $\mathrm{x}$ & $\mathrm{x}$ & $\mathrm{x}$ & & $\mathrm{x}$ & $\mathrm{x}$ & $\mathrm{x}$ & $\mathrm{x}$ & $\mathrm{x}$ & & $\mathrm{x}$ & & $\mathrm{x}$ & $\mathrm{x}$ \\
\hline $\begin{array}{l}\text { Waranty } \\
\text { period }\end{array}$ & & & & $\mathrm{x}$ & & & & & & & & & & & & & $\mathrm{x}$ & & & & & & & \\
\hline $\begin{array}{l}\text { Certification of } \\
\text { products }\end{array}$ & $\mathrm{x}$ & & & & & & & $\mathrm{x}$ & $\mathrm{x}$ & & & & & & & & $\mathrm{x}$ & & & $\mathrm{x}$ & $\mathrm{x}$ & & & \\
\hline Reputation & & $\mathrm{x}$ & $\mathrm{x}$ & $\mathrm{x}$ & $\mathrm{x}$ & $\mathrm{x}$ & & & & & & $\mathrm{x}$ & $\mathrm{x}$ & $\mathrm{x}$ & & $\mathrm{x}$ & & & $\mathrm{x}$ & & & & $\mathrm{x}$ & \\
\hline $\begin{array}{l}\text { Awards and } \\
\text { honors }\end{array}$ & & & & & & & $\mathrm{x}$ & & & & & & & & & & & & & & & & & \\
\hline $\begin{array}{l}\text { Communicatio } \\
n \text { system }\end{array}$ & & $\mathrm{x}$ & $\mathrm{x}$ & $\mathrm{x}$ & & & & & & $\mathrm{x}$ & & & $\mathrm{x}$ & $\mathrm{x}$ & & $\mathrm{x}$ & $\mathrm{x}$ & & & & $\mathrm{x}$ & & & \\
\hline $\begin{array}{l}\text { Speed of } \\
\text { response to } \\
\text { requirements }\end{array}$ & & & & & & & & & $\mathrm{x}$ & $\mathrm{x}$ & & & & & & $\mathrm{x}$ & & & $\mathrm{x}$ & $\mathrm{x}$ & $\mathrm{x}$ & $\mathrm{x}$ & & \\
\hline $\begin{array}{l}\text { Reactions to } \\
\text { reclamation }\end{array}$ & & & & & & & & & & & & & & & & $\mathrm{x}$ & & & & $\mathrm{x}$ & & & & $\mathrm{x}$ \\
\hline $\begin{array}{l}\text { Information } \\
\text { Technology }\end{array}$ & & & & & & & & & $\mathrm{x}$ & & & & & & & & & & & & & & & \\
\hline $\begin{array}{l}\text { Clean of } \\
\text { business }\end{array}$ & & & & & & & & & $\mathrm{X}$ & & & & $\mathrm{x}$ & & & & & & & & & & & $\mathrm{x}$ \\
\hline
\end{tabular}

A-Birgin 2003; B-Cebi \& Bayraktar, 2003; C-Chan \& Kumar, 2007; D-Dickson, 1996; E-Ellram, 1990; F-Gencer \& Gupinar, 2007; G-Hruska et.el, 2014; H-Hudymaciva et.al, 2013; J-Kahraman et.al, 2003; K-Kannan \& Choon, 2006; L-Kilic, 2013; M-Lee, 2009; N-Lim \& Chang, 2008; O-Muralidharan et.al, 2002; P-Ozbek, 2015; Q-Simpson et.el, 2002; R-Stevic et.al, 2015; S-Tam \& Tummala, 2001; T-Ting \& Chao, 2008; U-Uygun, 20013; V-Wang et.al, 2004; W-Weber er.al, 1991; X-Zeydan et.el, 2001. 


\section{METODE PENELITIAN}

\section{Jenis Penelitian}

Jenis penelitian yang peneliti lakukan merupakan sebuah penelitian terapan yaitu penelitian yang bertujuan untuk memberikan solusi atas permasalahan tertentu secara praktis. Penelitian ini tidak berfokus pada pengembangan sebuah ide, teori, atau gagasan, tetapi lebih berfokus kepada penerapan penelitian tersebut yaitu pada proses yang dapat membantu perusahaan menentukan vendor packaging yang terbaik.

\section{Metode Pengumpulan Data}

Metode pengumpulan data yang digunakan dalam penelitian ini menggunakan sumber data primer dan data sekunder. Data primer penelitian ini diperoleh dari hasil kuesioner, wawancara dan observasi. Data sekunder dalam penelitian ini diperoleh dari catatan-catatan penting tentang vendor yang sudah pernah dan sedang bekerjasama dengan perusahaan.

\section{Metode Pengembangan Sistem}

Dalam proses pengembangan sistem, peneliti menggunakan metode, metode waterfall merupakan metode yang sangat familiar dan sering digunakan oleh pengembang sebuah sistem informasi dikarenakan memiliki sifat ynga terstruktur dan mudah dipahami sebagai rangkain siklus hidup klasik (classic life cycle) pengembangan sebuah sistem informasi.

Metode waterfall merupakan sebuah metode pengembangan perangkat lunak/software yang dilakukan secara berurutan, terstruktur dan terus mengalir ke bawah (seperti air terjun) melewati semua fase pengembangan sistem, yaitu: fase perencanaan, fase pemodelan, fase implementasi, dan fase pengujian (Soleh et al., 2013).

\section{HASIL DAN PEMBAHASAN}

Tahapan perhitungan Decission Support System (DSS) dengan metode Fuzzy Analytic Hierarchy Process untuk proses penentuan vendor (pemasok) yaitu:

\section{Penyusunan Hirarki Masalah}

Metode penyusunan struktur hirarki permasalahan dari penelitian dimulai dari tujuan utama sebagai level teratas, kemudian ditentukan kriteria-kriteria yang sesuai sebagai bahan pertimbangan dan menilai semua alternatif pilihan yang ingin dibuat perangkingannya. Peneliti membuat beberapa kriteria dan alternative sesuai dengan kebutuhan penelitian ini sebagaimana gambar 1.

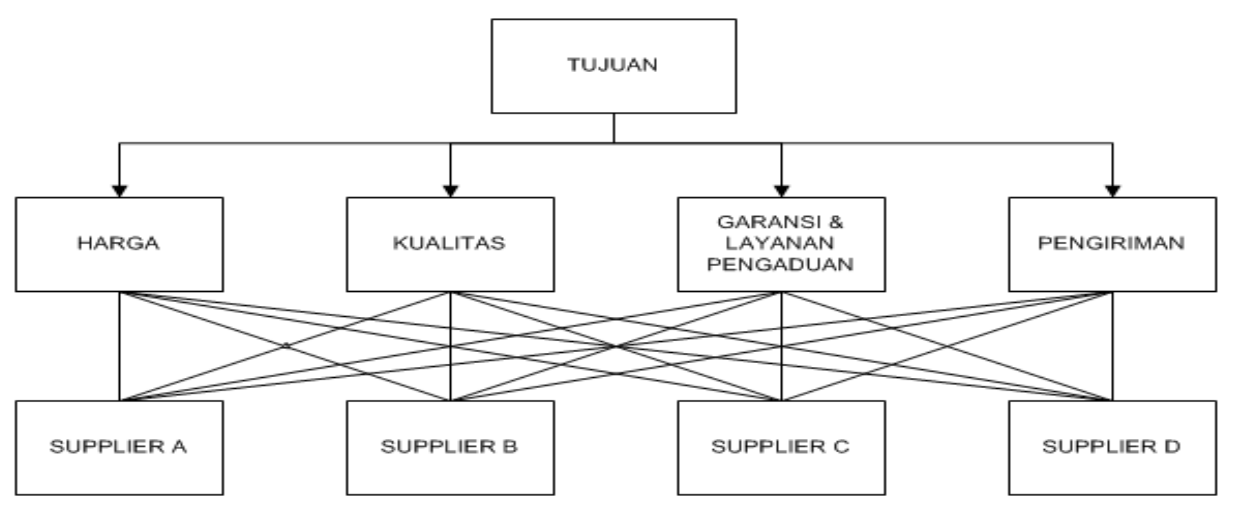

Gambar 1. Hirarki Kriteria dan Alternatif Penelitian

\section{Penyusunan matriks perbandingan berpasangan}

Langkah yang dilakukan dalam menentukan prioritas kriteria, pertama adalah menyusun perbandingan berpasangan dengan cara membandingkan seluruh kriteria untuk setiap sub sistem hirarki dengan berpasangan.
Selanjutnya perbadingan itu ditransformasikan bentuk matriks perbandingan berpasangan untuk analisis numeric dimana nilai numerik yang dikenakan untuk seluruh perbandingan diperoleh dari skala perbandingan 1-9 yang telah ditetapkan oleh Saaty, seperti tabel 3. 
Tabel 3. Tabel Skala Penilaian Perbandingan Berpasangan

\begin{tabular}{|c|c|c|}
\hline $\begin{array}{c}\text { Tingkat } \\
\text { Kepentingan }\end{array}$ & Definisi & Keterangan \\
\hline 1 & Sama Pentingnya & Kedua elemen mempunyai pengaruh yang sama \\
\hline 3 & $\begin{array}{l}\text { sedikit lebih penting } \\
\text { satu atas lainnya }\end{array}$ & $\begin{array}{l}\text { Pengalaman dan penilaian memihak satu sedikit } \\
\text { penting dibandingkan dengan pasangannya. }\end{array}$ \\
\hline 5 & Cukup Penting & $\begin{array}{l}\text { Pengalaman dan keputusan menunjukkan kesukaan } \\
\text { atas satu aktifitas lebih dari yang lain }\end{array}$ \\
\hline 7 & Sangat Penting & $\begin{array}{l}\text { Pengalaman dan keputusan menunjukkan kesukaan } \\
\text { yang kuat atas satu aktifitas lebih dari yang lain }\end{array}$ \\
\hline 9 & Mutlak lebih Penting & $\begin{array}{l}\text { Satu elemen mutlak lebih disukai dibandingkan } \\
\text { dengan pasangannya, tingkat keyakinan tertinggi. }\end{array}$ \\
\hline $2,4,6,8$ & $\begin{array}{l}\text { Nilai tengah diantara } \\
\text { dua nilai keputusan } \\
\text { yang berdekatan }\end{array}$ & Bila kompromi dibutuhkan \\
\hline Respirokal & Kebalikan & $\begin{array}{l}\text { Jika elemen i memiliki salah satu angka dari skala } \\
\text { perbandingan } 1 \text { sampai } 9 \text { yang telah ditetapkan oleh } \\
\text { Saaty ketika dibandingkan elemen } j \text {, maka j memiliki } \\
\text { kebalikannya ketika dibandingkan dengan elemen i }\end{array}$ \\
\hline
\end{tabular}

Hasil pembobotan kriteria diatas merupakan matriks yang besarnya nxn, dimana $n$ merupakan jumlah banyaknya kriteria.

$$
K=\left[\begin{array}{lll}
k 11 & k 12 & k 13 \\
k 21 & k 22 & k 23 \\
k 31 & k 32 & k 33
\end{array}\right]
$$

Keterangan:

$\mathrm{K}_{11}=$ Nilai dari kriteria 1 dibandingkan dengan kriteria 1

$\mathrm{K}_{12}=$ Nilai dari kriteria 1 dibandingkan dengan kriteria 2

$\mathrm{K}_{\mathrm{ij}}=$ Nilai dari kriteria ke i dibandingkan kriteria ke $\mathrm{j}$

Untuk setiap kriteria ke $\mathrm{i}$ dan $\mathrm{j}$, berlaku: $\mathrm{k}_{\mathrm{ii}}=$ 1 , dan $\mathrm{k}_{\mathrm{ij}}=\mathrm{k}_{\mathrm{ji}}{ }^{-11}$

\section{Sintesis matriks perbandingan berpasangan}

Lengkah selanjutnya melakukan proses perhitungan eigen vector dari setiap matriks perbandingan berpasangan. Nilai eigen vector merupakan bobot setiap elemen, langkah ini untuk mensintetis pilihan dalam penentuan prioritas elemen di tingkat hirarki terendah sampai pencapaian tujuan yang diinginkan.

\section{Menghitung konsistensi matriks}

Consistency ratio $(\mathrm{CI})$ merupakan parameter yang dipakai dalam rangka memeriksa perbandingan berpasangan yang telah dilakukan, apakah konsekuen atau tidak. Pengukuran konsistensi dari suatu matriks didasarkan atas eigen value maksimum, dimana nilai index konsistensi dihitung dengan rumus:

$$
C I=\frac{\pi \max -n}{n-1}
$$

Keterangan :

$\mathrm{CI}=$ rasio penyimpangan (deviasi) konsistensi (Consistency Index)

$\mathrm{n} \quad=$ Orde Matriks (banyaknya alternatif)

$\pi_{\max }=$ Nilai eigen terbesar dari matriks berordo $\mathrm{n}$

Apabila $\mathrm{Cl}$ bernilai nol, maka matriks perbandingan berpasangan tersebut konsisten. Batas ketidakkonsistenan yang telah ditetapkan ditentukan dengan menggunakan Rasio Konsisten (CR) yaitu perbandingan indeks konsisten dengan nilaiRandom Indeks (RI) yang didapat dari suatu eksperimen oleh Oak Ridge National Laboratory yang dikembangkan oleh Wharton School. 


\section{Penyusunan matriks penilaian $f u z z y$}

Empat tahap yang dilakukan dalam menentukan matriks penilaian fuzzy:

a. Membuat Struktur Hirarki Masalah

Pada struktur hirarki, tujuan yang ingin dicapai diletakan di level pertama, kriteria diletakan di level kedua, sub-kriteria diletakan di level ketiga dan alternatif diletakan di level terakhir.

b. Mengevaluasi Kriteria Tangible

Langkah-langkahnya adalah dengan membuat tabel yang berisi data kuantitatif yang dibagi menjadi lima interval, yang mana setiap interval sama dengan sebuah fuzzy number.

Tabel 4. Tabel Skala Rasio Fuzzy Number untuk Kriteria/Sub-Kriteria

\begin{tabular}{|c|c|}
\hline $\begin{array}{c}\text { Skala } \\
\text { Fuzzy }\end{array}$ & Kriteria/Sub kriteria \\
\hline 1 & Data kualitatif yang setara dengan skala 1 \\
\hline 3 & Data kualitatif yang setara dengan skala 3 \\
\hline 4 & Data kualitatif yang setara dengan skala 5 \\
\hline 7 & Data kualitatif yang setara dengan skala 7 \\
\hline 9 & Data kualitatif yang setara dengan skala 9 \\
\hline
\end{tabular}

c. Mengevaluasi Kriteria Intangible

Dalam mengevaluasi kriteria/sub-kriteria yang bersifat intangible, kesulitan yang dihadapi adalah kriteria/sub-kriteria tersebut biasanya tidak berupa data kuantitatif atau standar, sehingga pengambil keputusan sering memberikan nilai yang subjektif.

d. Matriks penilaian fuzzy

Proses berikutnya menghitung judgement score. Sub-skor $\widetilde{G}_{i j k}$ dapat dilihat pada tabel berikut:

Tabel 5. Sub-Skor dari Alternatif Relatif Terhadap Kriteria (chen 2005)

\begin{tabular}{|c|c|c|c|c|c|c|c|}
\hline \multirow{2}{*}{$\begin{array}{l}\text { Alter } \\
\text { natif }\end{array}$} & \multicolumn{3}{|c|}{$\mathrm{C}_{1}$} & \multicolumn{2}{|c|}{$\mathrm{C}_{2}$} & \multirow{2}{*}{$\ldots$} & \multirow{2}{*}{$\begin{array}{l}\mathrm{C}_{\mathrm{m}} \\
\mathrm{C}_{\mathrm{mq}} \\
\end{array}$} \\
\hline & $\mathrm{C}_{11}$ & $\mathrm{C}_{12}$ & $\mathrm{C}_{13}$ & $\mathrm{C}_{21}$ & $\mathrm{C}_{22}$ & & \\
\hline $\mathrm{A}_{1}$ & $\mathrm{C}_{111}$ & $\mathrm{C}_{112}$ & $\mathrm{C}_{113}$ & $\mathrm{C}_{121}$ & $\mathrm{C}_{122}$ & $\ldots$. & $\mathrm{C}_{1 \mathrm{mq}}$ \\
\hline $\mathrm{A}_{2}$ & $\mathrm{C}_{211}$ & $\mathrm{C}_{212}$ & $\mathrm{C}_{213}$ & $\mathrm{C}_{221}$ & $\mathrm{C}_{222}$ & $\ldots \ldots$ & $\mathrm{C}_{2 \mathrm{mq}}$ \\
\hline$\ldots$ & $\ldots$ & $\ldots$ & $\ldots$ & $\ldots$ & $\ldots$ & $\ldots$ & $\ldots$ \\
\hline$A_{n}$ & $\mathrm{C}_{\mathrm{n} 11}$ & $\mathrm{C}_{\mathrm{n} 12}$ & $\mathrm{C}_{\mathrm{n} 13}$ & $\mathrm{C}_{\mathrm{n} 21}$ & $\mathrm{C}_{\mathrm{n} 22}$ & & $\mathrm{C}_{\mathrm{nm}}$ \\
\hline
\end{tabular}

Persamaan berikut dapat digunakan untuk menjumlahkan sub-skor dari kriteria yang sama.

$\widetilde{G}_{i j}=\sum_{k=1}^{q} \widetilde{G}_{i j k}, i=1,2, \ldots n \quad j=1,2$, ... $m \quad k=1,2, \ldots q \quad$ (3)

Setelah seluruh sub-skor dijumlahkan, akan diperoleh matriks seperti berikut:

$$
\left(\begin{array}{c}
A 1 \\
A 2 \\
A(n)
\end{array}\right)=\left(\begin{array}{ccc}
\widetilde{G} 11 & \widetilde{G} 12 & \widetilde{G} m \\
\widetilde{G} 21 & \widetilde{G} 22 & \widetilde{G} 1 m \\
\widetilde{G}(n 1) & \widetilde{G}(n 2) & \widetilde{G} n m
\end{array}\right)
$$

Selanjutnya dilakukan proses normalisasi menggunakan persamaan yang dibuat oleh Chen dan Hwang (1992). Setiap skor yang ada pada matriks diatas dinormalisasi dengan persamaan berikut:

$$
\widetilde{a}_{i j}=\frac{\widetilde{G}_{i j}}{\sqrt{\sum_{i=1}^{n}\left(\widetilde{G}_{i j}\right)^{2}}}, j=1,2, \ldots, m(5)
$$

Setelah semua skor dinormalisasi, maka dapat diperoleh matriks penilaian fuzzy.

\section{Analisis sistem yang dikembangkan}

Sistem yang akan dibuat ini menggunakan sebuah tampilan dashboard agar pemilik perusahaan dapat dengan mudah membaca hasil atau laporan yang dikeluarkan oleh sistem. Dashboard tersebut akan menampilkan bobot kriteria, serta supplier terbaik berdasarkan perhitungan metode Fuzzy AHP.

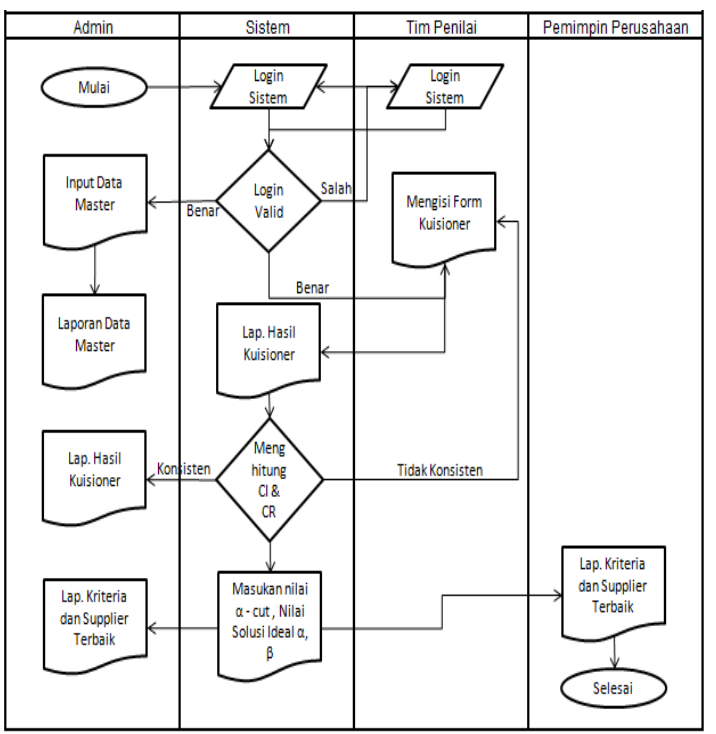

Gambar 2. Gambar DAD sistem yang dikembangkan 


\section{Use case sistem yang dikembangkan}

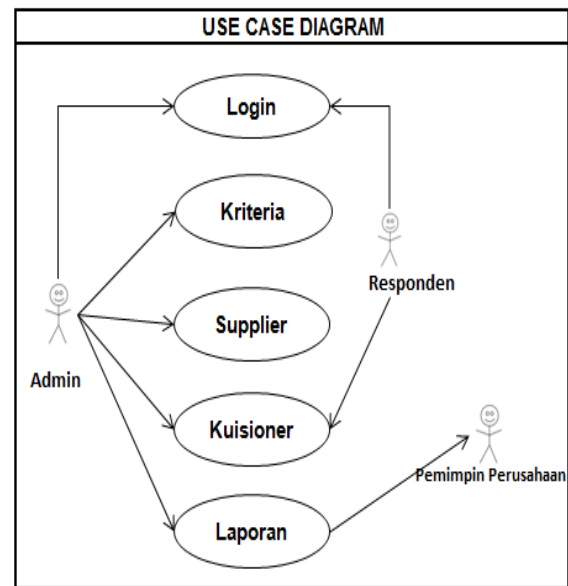

Gambar 3. Gambar use case sistem yang dikembangkan

Keterangan :

a. Responden :Melakukan penilaian terhadap kuisioner bobot dan kriteria

b. Admin :Melakukan penginputan data master kedalam sistem, mengolah data kuisioner kedalam perhitungan AHP dan FAHP didalam sistem serta melaporkan hasil perhitungannya kepada Manager.

c. Manager : Melihat hasil akhir terhadap pemilihan yang dilakukan oleh sistem.

8. Activity Diagram sistem yang dikembangkan

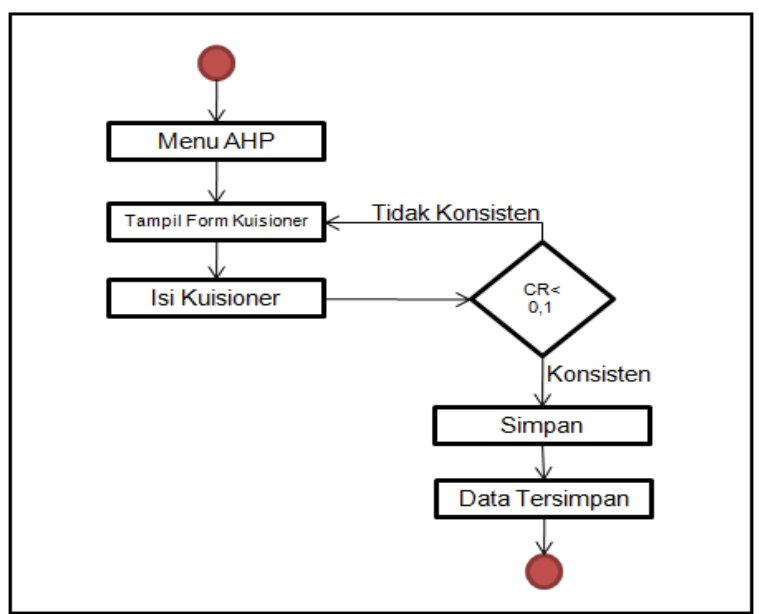

Gambar 4. Gambar activity diagram penilaian
9. Tampilan sistem yang dikembangkan a. Tampilan Menu Login

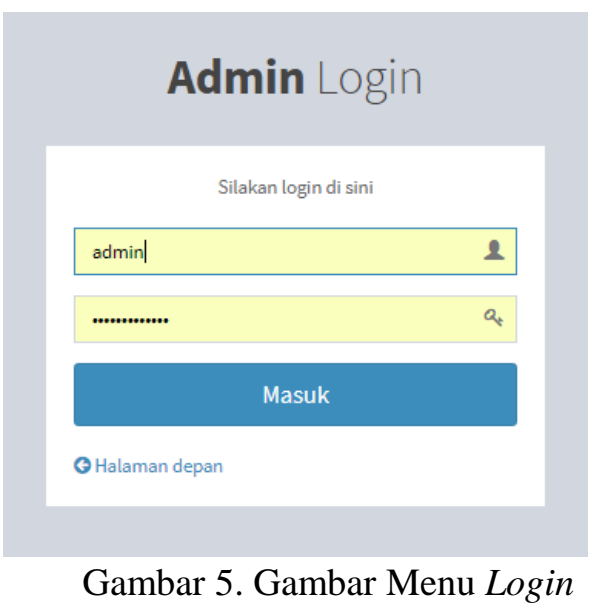

\section{b. Tampilan menu utama sistem}

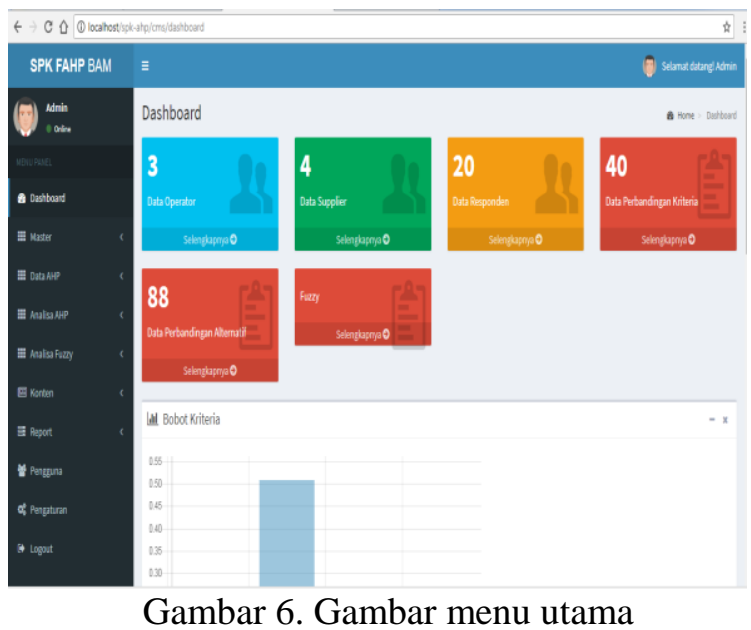

c. Tampilan menu master sistem

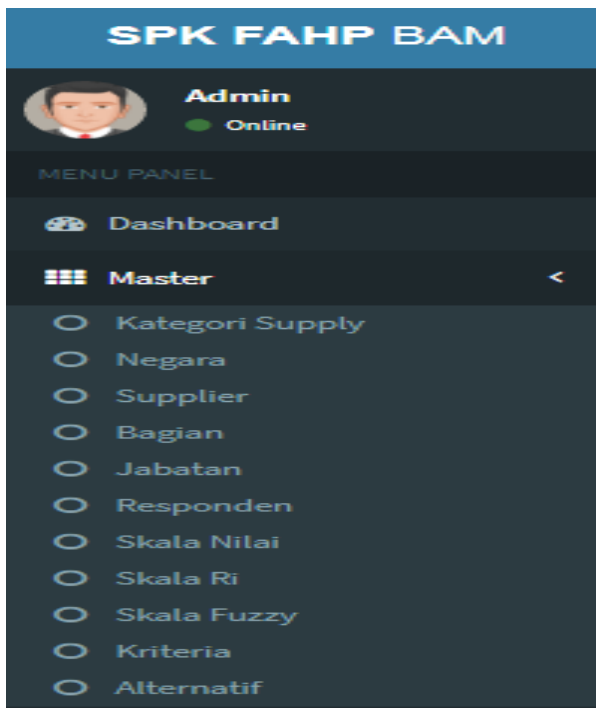

Gambar 7. Gambar menu master sistem 


\section{d. Tampilan menu master alternatif}

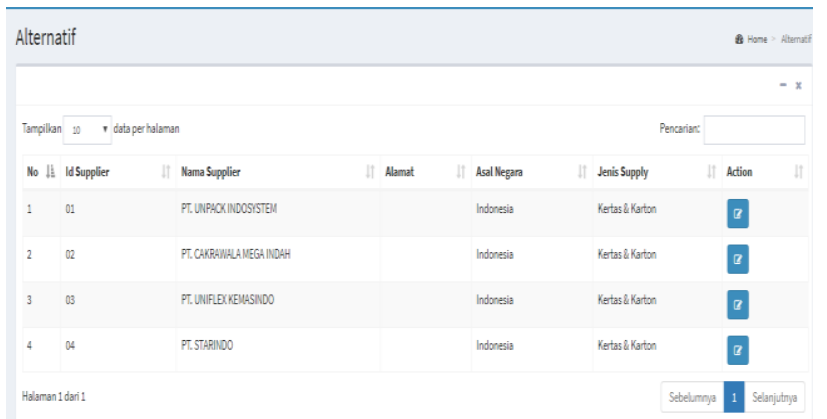

Gambar 8. Gambar menu master alternatif

\section{e. Tampilan Menu Analisa AHP}

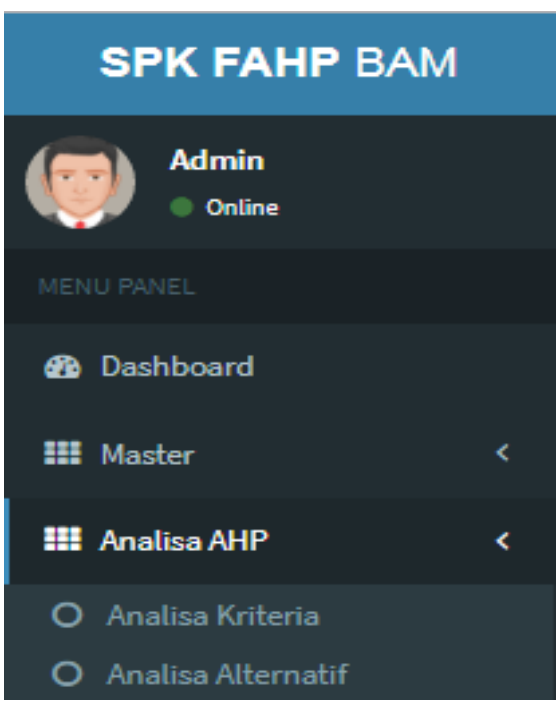

Gambar 9. Gambar tampilan menu analisa AHP

\section{f. Tampilan laporan hasil analisa kriteria}
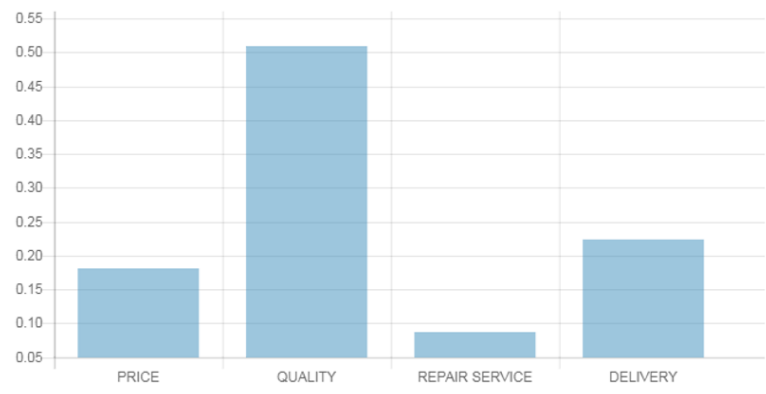

Gambar 10. Gambar laporan hasil analisa kriteria

\section{Pengujian Sample Data}

Untuk melihat dan menguji hasil proses perhitungan metode Fuzzy Analytic Hierarchy Process berdasarkan kriteria yang ditentukan menggunakan sistem yang dikembangkan dalam penelitian ini, peneliti menggunakan 4 data vendor yaitu: PT. Unipack Indosystem, PT. Cakrawala Mega Indah, PT. Uniflex Kemasindo, PT Starindo, dan didapat hasil perhitungan:

\begin{tabular}{|c|c|c|c|}
\hline ALERNATIF & SOLUSI IDEAL & SOLUSIDEALNEGATIF & NLAA PERFORMAFINAL \\
\hline PT.UNPACK NDOSYSTEM & 0.266 & 0.061 & 0.187 \\
\hline QUALITY & 0.088 & 0.203 & 0.697 \\
\hline REPAR SERNCE & 0.118 & 0.165 & 0.583 \\
\hline DELLVERY & 0.131 & 0.227 & 0.634 \\
\hline
\end{tabular}

Gambar 11. Gambar laporan hasil analisa kriteria

\section{KESIMPULAN}

1. Berdasarkan pengolahan data menggunakan sistem penunjang keputusan yang dikembangkan dengan metode Fuzzy Analytical Hierarchy Process didapat hasil yang menunjukan keputusan pemilihan supplier kemasan (box packaging) terbaik yang sesuai dengan data kriteria yang ada.

2. Dari kriteria harga (price), kualitas (quality), layanan perbaikan (repair service) dan pengantaran (delivery) yang digunakan, didapat informasi bahwa kriteria kualitas (quality) adalah kriteria tertinggi bobot 0.509 , urutan kedua adalah kriteria pengiriman (delivery) bobot 0,224, kemudian harga (price) bobot 0,181 serta terakhir kriteria layanan perbaikan (repair service) bobot 0,086 .

3. Sistem penunjang keputusan yang dikembangkan telah dapat membantu pimpinan perusahaan perusahaan melakukan pengambilan keputusan.

\section{REFERENSI}

Fitriawati, N., Herdiansah, A., \& Gunawan, A. (2019). Sistem Informasi Program Keluarga Harapan Studi Kasus Kecamatan Kosambi Tangerang. Jurnal Teknik Informatika (JIKA) Universitas Muhammadiyah Tangerang, 3(2), 21-26.

Herdiansah, A. (2020). Sistem Pendukung Keputusan Referensi Pemilihan Tujuan Jurusan teknik Di Perguruan. Jurnal MATRIK, 19(2), 223-234. 
Herdiansah, A., Handayani, N., \& Kurniawan, A. (2019). Development of Decision Support Systems Selection of Employee Acceptance Using Weighted Product Method. Journal of Information System and Informatics, 1(2), 87-97.

Kotler, P., \& Amstrong, G. (2012). Principles of Marketing (Ed. 14th). Pearson: Prentice Hall - New Jersey.

Saraswat, D., \& Chaurasia, B. K. (2013). AHP based trust model in VANETs. Proceedings - 5th International Conference on Computational Intelligence and Communication Networks, CICN 2013, 391-393. https://doi.org/10.1109/CICN.2013.8 6

Soleh, Dewi, M. A., Arfiah, \& Asdin. (2013). Metode Peninjauan Dashboard Dari Business Intelligence Untuk Membuat Keputusan Lebih Baik. Seminar Nasional Teknologi Informasi Dan Multimedia, 13-18.

Stevic, Z. (2017). Criteria for supplier selection: A literature review. Nternational Association of Scientific Innovation and Research (IASIR), 19(1), 23-27.

Sugiyono. (2013). Metode Penelitian Kombinasi (mixed Methodes) (Ed.1). Alfabeta - Bandung.

Yaraghi, N., Tabesh, P., Guan, P., \& Zhuang, J. (2015). Comparison of AHP and Monte Carlo AHP under different levels of uncertainty. IEEE Transactions on Engineering Management, 62(1), 122-132. https://doi.org/10.1109/TEM.2014.23 60082

Yoserizal, Y. (2012). Integrasi Metode Dematel (Decision Making Trial and Evaluation Laboratory) dan ANP (Analytical Network Process) Dalam Mengevaluasi Kinerja Supplier di PT. XYZ. In Digital Library ITS. Institut Teknologi Sepuluh Nopember. 